\title{
DIAGONAL EXPANSION AND CONTRACTION OF A CIRCULAR TUNNEL DURING EARTHQUAKES
}

\author{
Kazuo KONAGAI 1 \\ ${ }^{1}$ Member of JSCE, Dr. Eng., Professor, Inst. of Industrial Science, University of Tokyo \\ (Roppongi 7-22-1, Minato-ku, Tokyo 106, Japan)
}

\begin{abstract}
Long term earthquake observations at different tunnel sites within a variety of alluvial soil deposits have clearly demonstrated that a circular tunnel is liable to deform in such a way that its two diagonal diameters crossing each other expand and contract alternately. Based on this knowledge, the soil-tunnel interaction for this particular vibration mode is investigated. The soil surrounding a tunnel is assumed to be a homogeneous elastic medium, and two extreme boundary conditions on the soil-tunnel interface are considered; the condition of fixed tangential strain and the shear stress-free condition. The former case suggests a firm bond between the tunnel lining and the soil, whereas the latter case is associated with an artificial slippery soiltunnel interface.
\end{abstract}

Key Words : dynamic soil-tunnel interaction, seismic isolation system, kinematic interaction, alternate expansion and contraction

\section{INTRODUCTION}

The South-Hyogo Earthquake of Jan. 17, 1995 did serious damage to some subway stations in Kobe ${ }^{1)}$, and showed again the importance of estimating the motion of a soil deposit surrounding an underground structure. Use of a finite element method with wave transmitting boundaries is a general and direct approach to analyzing the soil-tunnel interaction. The direct method, however, requires a computer program that can treat the behavior of both a tunnel and the surrounding soil with equal rigor. Moreover, variation of the soil profile in a 3D expanse should be provided for the analysis. Hence, there yet remains an important place for simple approaches even in these days of highly manipulative numerical solutions to problems of increasing complexity.

Among a number of simplified approaches, Multistep methods have been used for evaluating the earthquake resistance of an underground structure within a soft soil deposit. These methods use the principle of superposition to isolate two primary causes of soil-structure interaction, that is, the inability of a tunnel to match the free-field deformation (kinematic interaction) and the effect of inertia force of the structure on the response of the surrounding soil (inertia interaction). When a hollow structure like a tunnel is concerned, inertia interaction is often of less importance than kinematic interaction. For this reason, it is usual in a practical design process that free-field ground displacement is applied through Winkler-type soil springs to a tunnel in order to evaluate stress patterns induced within its structure members. The evaluation of soil springs, however, is often as cumbersome as the analysis of the whole soil-structure system. Moreover, the obtained stiffness depends on the vibration mode of the tunnel and the excitement frequency as well.

Long term earthquake observations at different tunnel sites within a variety of alluvial soil deposits have demonstrated that a circular tunnel is liable to deform in such a way that its two diagonal diameters crossing each other expand and contract alternately ${ }^{2}$, which fact has been found to be linked with the motion of the surrounding soil at resonance. It is therefore worth attempting to derive soil stiffness assuming this particular vibration mode. Two extreme boundary conditions are considered on the 
wall of the hollow; the condition of fixed tangential strain and the shear stress-free condition. The former case suggests a firm bond between a tunnel lining and the surrounding soil, whereas the latter case is associated with an artificial slippery soil-lining interface reducing shearing stress on the lining ${ }^{3)}$. The derivation is presented here in a brief form as it is similar to the elastic solution ${ }^{4), 5)}$; it is given in more detail in Ref. 6).

\section{DERIVATION OF SOIL STIFFNESS}

The soil deposit discussed in this chapter is a twodimensional medium of an infinite extent (Fig. 1). The governing equations of a visco-elastic medium undergoing harmonic motion are expressed in the cylindrical coordinates as:

$$
\begin{aligned}
& (\lambda+2 \mu) \frac{\partial \Delta e^{i \omega t}}{\partial r}-\frac{2 \mu}{r} \frac{\partial \Omega_{z} e^{i \omega t}}{\partial \theta}=\rho \frac{\partial^{2} u_{r} e^{i \omega t}}{\partial t^{2}} \\
& (\lambda+2 \mu) \frac{\partial \Delta e^{i \omega t}}{r \partial \theta}+2 \mu \frac{\partial \Omega_{z} e^{i \omega t}}{\partial r}=\rho \frac{\partial^{2} u_{\theta} e^{i \omega t}}{\partial t^{2}}
\end{aligned}
$$

where,

$$
\begin{aligned}
& \Delta=\frac{1}{r} \frac{\partial}{\partial r}\left(r u_{r}\right)+\frac{1}{r} \frac{\partial u_{\theta}}{\partial \theta} \\
& \Omega_{z}=\frac{1}{2 r}\left(\frac{\partial}{\partial r}\left(r u_{\theta}\right)-\frac{\partial u_{r}}{\partial \theta}\right)
\end{aligned}
$$

Here $\lambda, \mu=$ complex Lame's constants whose imaginary parts describe soil viscosity, $\rho=$ density of soil, $i=\sqrt{-1}, \omega=$ circular excitement frequency, $t$ $=$ time and $u_{r}, u_{\theta}=$ displacements in $r$ and $\theta$ directions, respectively. From eqs. (1a) and (1b), the displacements and the soil reaction to the motion of the cylindrical hollow can be obtained by means of the following two potential functions:

$$
\phi=\sum_{m=0,1, \ldots}^{\infty} \phi_{m} \text { and } \psi=\sum_{m=0,1, \ldots}^{\infty} \psi_{m}
$$

The functions $\phi_{m}$ and $\psi_{m}$ are found to have the following forms:

$$
\begin{aligned}
& \phi_{m}=K_{m}(q r) \cdot\left(A_{c, m} \cos m \theta+A_{s, m} \sin m \theta\right) \\
& \psi_{m}=K_{m}(s r) \cdot\left(B_{c, m} \cos m \theta+B_{s, m} \sin m \theta\right)
\end{aligned}
$$

where, $A_{c, m}, A_{s, m}, B_{c, m}$ and $B_{s, m}$ are unknown constants, $K_{m}$ is the modified Bessel function of order $m$, and

$$
q^{2}=-\frac{\rho \omega^{2}}{\lambda+2 \mu}=-\frac{\omega^{2}}{v_{p}{ }^{2}}, s^{2}=-\frac{\rho \omega^{2}}{\mu}=-\frac{\omega^{2}}{v_{s}{ }^{2}}
$$

It is assumed that a circular cross-section of a cylindrical hollow of radius $r_{0}$ deforms in such a way that its two diagonal diameters orthogonal to each other $\left(\theta= \pm 45^{\circ}\right)$ alternately expand and contract.

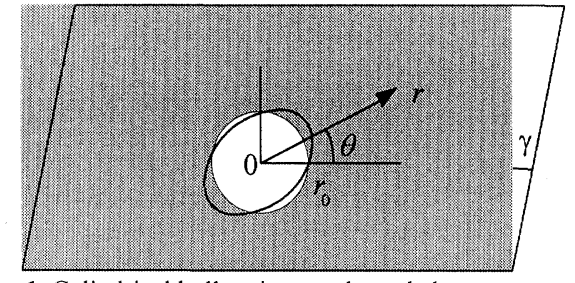

Fig. 1 Cylindrical hollow in an unbounded medium under shearing

This calls for $m=2$ and $A_{c, m}=B_{s, m}=0$ in the above equations. Thus the displacements are found to be:

$$
\left\{\begin{array}{l}
u_{r} \\
u_{\theta}
\end{array}\right\}=\left\{\begin{array}{l}
\hat{u}_{r} \sin 2 \theta \\
\hat{u}_{\theta} \cos 2 \theta
\end{array}\right\}
$$

where,

$$
\left\{\begin{array}{l}
\hat{u}_{r} \\
\hat{u}_{\theta}
\end{array}\right\}=\left[\begin{array}{ll}
U_{r, A} / r & U_{r, B} / r \\
U_{\theta, A} / r & U_{\theta, B} / r
\end{array}\right]\left\{\begin{array}{l}
A_{s, 2} \\
B_{c, 2}
\end{array}\right\}
$$

and

$$
\begin{aligned}
& U_{r, A}=-2 K_{0}(q r)-\left(\frac{4}{q r}+q r\right) K_{1}(q r) \\
& U_{r, B}=-2 K_{0}(s r)-\frac{4}{s r} K_{1}(s r) \\
& U_{\theta, A}=2 K_{0}(q r)+\frac{4}{q r} K_{1}(q r) \\
& U_{\theta, B}=2 K_{0}(s r)+\left(\frac{4}{s r}+s r\right) K_{1}(s r)
\end{aligned}
$$

Normal and shear stress components are then obtained as:

$$
\left\{\begin{array}{l}
\sigma_{r r} \\
\tau_{r \theta}
\end{array}\right\}=\left\{\begin{array}{l}
\hat{\sigma}_{r r} \sin 2 \theta \\
\hat{\tau}_{r \theta} \cos 2 \theta
\end{array}\right\}
$$

where,

$$
\left\{\begin{array}{l}
\hat{\sigma}_{r r} \\
\hat{\tau}_{r \theta}
\end{array}\right\}=\frac{\mu}{r^{2}}\left[\begin{array}{ll}
T_{r r, A} & T_{r r, B} \\
T_{r \theta, A} & T_{r \theta, B}
\end{array}\right]\left\{\begin{array}{c}
A_{s, 2} \\
B_{c, 2}
\end{array}\right\}
$$

and

$$
\begin{aligned}
T_{r r, A}= & \frac{\lambda}{\mu}(q r)^{2}\left\{K_{0}(q r)+\frac{2}{q r} K_{1}(q r)\right\}+ \\
& \left(2(q r)^{2}+12\right) K_{0}(q r)+\left(6 q r+\frac{24}{q r}\right) K_{1}(q r) \\
T_{r r, B}= & 12 K_{0}(s r)+\left(4 s r+\frac{24}{s r}\right) K_{1}(s r) \\
T_{r \theta, A}= & -12 K_{0}(q r)-\left(4 q r+\frac{24}{q r}\right) K_{1}(q r) \\
T_{r \theta, B}= & -\left((s r)^{2}+12\right) K_{0}(s r)-\left(4 s r+\frac{24}{s r}\right) K_{1}(s r)
\end{aligned}
$$

From eqs. (7) and (10), $\hat{\sigma}_{r r}$ and $\hat{\tau}_{r \theta}$ are finally expressed in terms of $\hat{u}_{r}$ and $\hat{u}_{\theta}$ as:

$$
-\left\{\begin{array}{l}
\hat{\sigma}_{r r} \\
\hat{\tau}_{r \theta}
\end{array}\right\}=\frac{\mu}{r}\left[\begin{array}{ll}
S_{r r} & S_{r \theta} \\
S_{\theta r} & S_{\theta \theta}
\end{array}\right]\left\{\begin{array}{l}
\hat{u}_{r} \\
\hat{u}_{\theta}
\end{array}\right\}
$$


where

$$
\begin{aligned}
& S_{r r}=\left(-T_{r r, A} U_{\theta B}+T_{r r, B} U_{\theta A}\right) / S \\
& S_{r \theta}=\left(T_{r r, A} U_{r B}-T_{r r, B} U_{r A}\right) / S \\
& S_{\theta r}=\left(-T_{r \theta, A} U_{\theta B}+T_{r \theta, B} U_{\theta A}\right) / S \\
& S_{\theta \theta}=\left(T_{r \theta, A} U_{r B}-T_{r \theta, B} U_{r A}\right) / S
\end{aligned}
$$

and

$$
S=U_{r A} U_{\theta B}-U_{\theta A} U_{r B}
$$

\section{EFFECT OF SOIL-TUNNEL INTERACTION}

The motion of a soil deposit at resonance is, in general, the most responsible for this inclined elliptic vibration mode of a cylindrical hollow. The thickness $H$ of this layer is thus considered to be about one fourth of the stationary shear wave length $L$, i.e.

$$
H \cong L / 4=\pi v_{s} / 2 \omega_{0}
$$

where $f_{0}=\omega_{0} / 2 \pi=$ resonance frequency of the soil deposit. Needless to say, the tunnel diameter $2 r_{0}$ should not be greater than the surface soil thickness $H$. This condition calls for:

$$
\frac{s r_{0}}{i}=\frac{\omega_{0} r_{0}}{v_{s}}<\frac{\pi}{4}
$$

and limits the following discussion within this range of $s r_{0}$. In the following discussion, the concept of a multi-step method, that has been mentioned briefly in the introduction, is employed to evaluate the soiltunnel interaction.

First, the motion of the cylindrical hollow, which is not affected by the presence of a tunnel lining, is to be obtained. Though its rigorous solution is available in a number of papers ${ }^{5}$, radial and tangential displacements $u_{r, \text { soil }}$ and $u_{\theta \text {,soil }}$ are tentatively approximated by the static solutions for a cylindrical cavity inclusion in an unbounded medium under alternate shearing (Fig. 1), because the tunnel's diameter is expected to be noticeably smaller than the predominant wave length in many cases encountered. Therefore,

$$
\begin{aligned}
& u_{r, \text { soil }} \cong \hat{u}_{r, \text { soil }} \sin 2 \theta \\
& u_{\theta, \text { soil }} \cong \hat{u}_{r, \text { soil }} \cos 2 \theta
\end{aligned}
$$

where, $\hat{u}_{r, \text { soil }}=\hat{u}_{\theta, \text { soil }}\left(=\hat{u}_{\text {soil }}\right)=2 \gamma r_{0}(1-v)$ and $\gamma$ is the applied shear strain (Fig. 1). It is noted in eq. (16) that $\hat{u}_{r, \text { soil }}$ and $\hat{u}_{\theta \text {,soil }}$ are identical to each other irrespective of Poisson's ratio. Thus, $\hat{u}_{\text {soil }}$ is viewed as a representative displacement parameter of soil. The tunnel lining is then assumed to have a perfect bond with its surrounding soil, and to be stiff enough in its tangential direction for the tangential strain $\varepsilon_{\theta \theta \text {,lining }}$ to be kept zero at the wall of the lining. Thus, the lining's displacements $u_{r, \text { lining }}$ and $u_{\theta \text {,lining }}$ eventually satisfy the following equation at $r=r_{0}$ :

$$
\varepsilon_{\theta \theta, \text { lining }}=\frac{1}{r} \frac{\partial u_{\theta, \text { lining }}}{\partial \theta}+\frac{u_{r, \text { lining }}}{r}=0
$$

Substituting equation (6) into equation (17) yields:

$$
\hat{u}_{r, \text { lining. }}=2 \hat{u}_{\theta, \text { lining }}\left(=\hat{u}_{\text {lining }}\right) \text { at } r=r_{0}
$$

The soil-tunnel lining interaction thus causes the displacement parameters of the stress-free cylindrical cavity to deviate from $\hat{u}_{r, \text { soil }}$ and $\hat{u}_{\theta \text {,soil }}$ by $\hat{u}_{r}$ and $\hat{u}_{\theta}$, respectively, where,

$$
\hat{u}_{r}=\hat{u}_{\text {lining }}-\hat{u}_{\text {soil }} \text { and } \hat{u}_{\theta}=\hat{u}_{\text {lining }} / 2-\hat{u}_{\text {soil }}
$$

Substituting eqs. (19a) and (19b) in eq. (12) yields soil reactions to the tunnel lining as:

$$
-\left\{\begin{array}{c}
\hat{\sigma}_{r r} \\
\hat{\tau}_{r \theta}
\end{array}\right\}=\frac{\mu}{r_{0}}\left[\begin{array}{ll}
S_{r r} & S_{r \theta} \\
S_{\theta r} & S_{\theta \theta}
\end{array}\right]\left\{\begin{array}{c}
\hat{u}_{\text {lining }}-\hat{u}_{\text {soil }} \\
\hat{u}_{\text {lining }} / 2-\hat{u}_{\text {soil }}
\end{array}\right\}
$$

Assuming the tunnel lining to be a circular Bernoulli-Euler beam, its displacement parameter $\hat{u}_{\text {lining }}$ is expressed in terms of $\hat{\sigma}_{r r}$ and $\hat{\tau}_{r \theta}$ as:

$$
\hat{u}_{\text {lining }}=\frac{r_{0}{ }^{4}}{18 E I}\left[\begin{array}{ll}
2 & 1
\end{array}\right]\left[\begin{array}{c}
\hat{\sigma}_{r r} \\
\hat{\tau}_{r \theta}
\end{array}\right]
$$

where, $E I=$ bending stiffness of the lining. From eqs. (20) and (21), the following equation is finally obtained:

$$
\frac{\hat{u}_{\text {lining }}}{\hat{u}_{\text {soil }}}=\frac{\xi\left(2 S_{r r}+2 S_{r \theta}+S_{\theta r}+S_{\theta \theta}\right)}{\left\{1+\xi\left(2 S_{r r}+S_{r \theta}+S_{\theta r}+\frac{S_{\theta \theta}}{2}\right)\right\}}
$$

where, $\xi=\frac{\mu r_{0}{ }^{3}}{18 E I}$.

The absolute value of $\hat{u}_{\text {lining }} / \hat{u}_{\text {soil }}$ shows the extent to which the tunnel lining is deformed by the given motion of the surrounding soil. Since $\hat{u}_{\text {soil }}$ in eq. (16) includes $\gamma r_{0}$, this value is also noticed to be proportional to the strain ratio $\left(\hat{u}_{\text {lining }} / r_{0}\right) / \gamma$, and thus, is considered to be an appropriate index for examining the soil-tunnel interaction effect.

Another possible extreme case is worth considering; a case of artificial slippery soil-tunnel interface, which condition yields: 


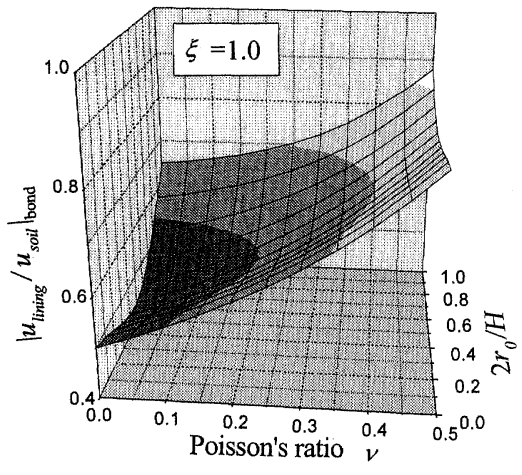

Fig. 2 Ratio between lining deformation and soil motion at resonance

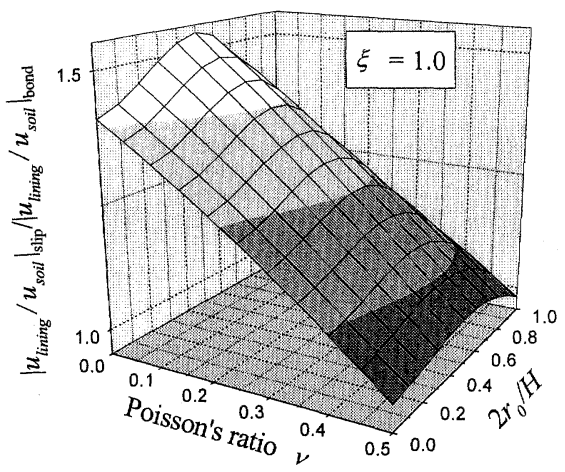

Fig. 3 Effect of introducing a slippery soil-tunnel interface

$$
\frac{\hat{u}_{\text {lining }}}{\hat{u}_{\text {soil }}}=\frac{2 \xi\left(S_{r r}-\frac{S_{r \theta} S_{\theta r}}{S_{\theta \theta}}\right)}{\left\{1+2 \xi\left(S_{r r}-\frac{S_{r \theta} S_{\theta r}}{S_{\theta \theta}}\right)\right\}}
$$

In either case, the index $\left|\hat{u}_{\text {lining }} / \hat{u}_{\text {soil }}\right|$ is a function of three parameters, namely, Poisson's ratio of soil, $v$, relative soil stiffness $\xi$ (eq. (23).) and $\omega r_{0} / v_{s}$. When the motion of the soil is at resonance, $\omega r_{0} / v_{s}$ is noticed to be identical to $(\pi / 4) \cdot 2 r_{0} / H$. Therefore, $2 r_{0} / H$, namely, the ratio between a tunnel diameter and the thickness of a surface layer is readily used in place of $\omega r_{0} / v_{s}$ to describe $\left|\hat{u}_{\text {lining }} / \hat{u}_{\text {soil }}\right|$. Fig. 2 shows the variation of the index $\left|\hat{u}_{\text {lining }} / \hat{u}_{\text {soil }}\right|_{\text {bond }}$ for the perfect-bonded lining case. The variation of the index with respect to $2 r_{0} / H$ is rather small when compared to that with

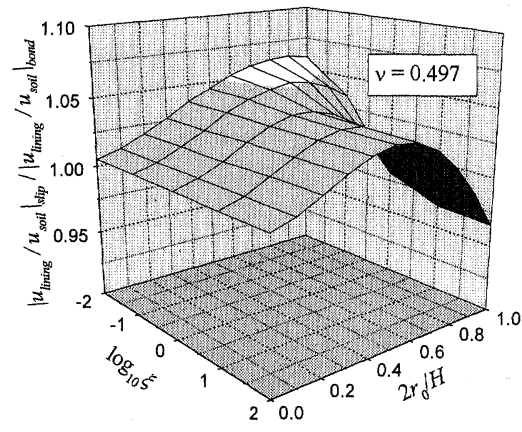

Fig. 4 Effect of introducing a slippery soil-tunnel interface

Poisson's ratio. The index increases as Poisson's ratio comes close to 0.5 , indicating an increase in the strain induced within the lining.

The index $\left|\hat{u}_{\text {lining }} / \hat{u}_{\text {soil }}\right|_{\text {slip }}$ for the case of an artificial slippery soil-tunnel interface (eq. (24)) is divided by $\left|\hat{u}_{\text {lining }} / \hat{u}_{\text {soil }}\right|_{\text {bond }}$ to examine the effect of introducing the slippery interface. The variation of this ratio $\left|\hat{u}_{\text {lining }} / \hat{u}_{\text {soil }}\right|_{\text {slip }} /\left|\hat{u}_{\text {lining }} / \hat{u}_{\text {soil }}\right|_{\text {bond }}$ with respect to both Poisson's ratio and $2 r_{0} / H$ is shown in Fig. 3. In this figure, relative soil stiffness $\xi$ is set at 1 . As Poisson's ratio of the soil comes close to 0.5 , shear stress $\hat{\tau}_{r \theta}$ converges on zero, and eventually, setting the shear stress free causes little difference. As Poisson's ratio decreases, however, it exhibits more the reverse effect of increasing the deformation of the lining.

Fig. 4 shows the variation of $\left|\hat{u}_{\text {lining }} / \hat{u}_{\text {soil }}\right|_{\text {slip }}$ / $\left|\hat{u}_{\text {lining }} / \hat{u}_{\text {soil }}\right|_{\text {bond }}$ with respect to both $\xi$ and $2 r_{0} / H$. Since Poisson's ration is set at 0.497 close to 0.5 , the variation of this ratio with $\xi$ is very small and is about identical to 1 particularly at smaller values of $2 r_{0} / H$.

Setting the shear stress free on the soil-tunnel interface leads to redistribution of stress, and the normal stress on the lining is increased. As has been shown in eq. (21), the normal stress is twice as responsible for the lining's deformation as the shear stress is. The tunnel isolation effect is, thus, not satisfactory in the above examples. It is, however, not readily concluded that tunnel isolation has no advantage in that strain components within a lining are reduced. Tunnel isolation, at least, is expected to 
reduce tunnel axial strain considerably ${ }^{3)}$. Furthermore, its effect depends on other factors like expansion and contraction of soft coating materials that spread over tunnel linings. These factors have been ignored in the present approach as they are beyond the scope of this note, but will be discussed in later publication.

\section{CONCLUSIONS}

It has been observed through long-term observations that a circular tunnel deforms during an earthquake in such a way that its diagonal diameters $\left(\theta= \pm 45^{\circ}\right)$ alternately expand and contract. Based on this knowledge, the soil-tunnel interaction for this particular vibration mode was investigated. Narrowing down vibration modes for discussion to this particular and the most important mode, the soil stiffness becomes completely independent of $\theta$, thus allowing the soil reaction to be described in terms of discrete springs of Winkler type spreading uniformly over the entire soil-tunnel interface. The index $\left|\hat{u}_{\text {lining }} / \hat{u}_{\text {soil }}\right|$, showing the extent to which the tunnel lining is deformed by the given motion of the surrounding soil, was demonstrated to be an appropriate index for examining the soil-tunnel interaction effect. Two extreme boundary conditions were discussed; the condition of fixed tangential strain and the shear stress-free condition on the soiltunnel interface. The latter case is associated with an artificial slippery soil-tunnel interface. It has been shown that reducing the shear stress on the soiltunnel interface causes little difference when
Poisson's ratio is close to 0.5 , whereas, as Poisson's ratio decreases, it can exhibit more the reverse effect of increasing the deformation of the lining. The effect, however, depends on other ignored factors like expansion and contraction of soft coating materials that spread over tunnel linings. Further detailed study on this point will be addressed in later publication.

\section{REFERENCES}

1) Iida, H., Hiroto, T., Yoshida, N. and M. Iwafuji: Damage to Daikai Subway Station, Special Issue of Soils and Foundations, Japanese Geotechnical Society, pp. 283-300, 1996.

2) Tamura, C. and Kato, K.: A Study on Deformation of Tunnels during Earthquakes, Recent Advances in Lifeline Earthquake Engineering in Japan, ASME, pp. 151-158, 1980.

3) Suzuki, T. and Tamura, C.: Proposal of a Seismic Isolation Structure for Urban Tunnels and the Method to Evaluate its Isolation Effect, Jour., Structural mechanics and Earthquake Engineering, No. 525/I-33, JSCE, pp. 275-286, 1995.

4) Nogami, T. and Novak, M.: Resistance of Soil to a Horizontally Vibrating Pile, Earthquake Engineering and Structural Dynamics, Vol. 5, pp. 249-261, 1977.

5) Pao, Y. H. and Mow, C. C.: Diffraction of Elastic Waves and Dynamic Stress Concentrations, Crane Russak, New York, 1973.

6) Konagai, K.: Effect of Seismic Isolation for a Circular Tunnel Alternately Expanding and Contracting in its Diagonal Directions, Proc., $1^{\text {st }}$ Colloquium on Vibration Reduction and Control, JSCE, pp. 179-183, 1996.

7) Muir Wood, A. M. : The Circular Tunnel in Elastic Ground, Geotechnique, 25, No. 1, pp. 115-127, 1975.

(Received April 16, 1997)

$$
\begin{gathered}
\text { 傾いた棈円状に変形するトンネルと地盤の相互作用 } \\
\text { 小長井一男 }
\end{gathered}
$$

沖積地盤中の円形断面のトンネルは地震時に地盤のせん断変形に追随し左右交互に傾いた楕円状の変 形を繰り返す.このノートではこのような円孔の変形モードを規定して一様地盤のインピーダンスを周波 数領域で求めている。このインピーダンスは, 円孔の変形モードを規定したことから円周に沿って一様な Winkler型の離散ばねで表現できる。 さらに相互作用がトンネルライニングに及ぼす効果を評価するイン デックスを提示し，ライニングと地盤が完全に付着した状態，およびの両者の間の摩擦を切った場合の相 互作用効果を検討した. ただ円孔壁面で摩擦を切るだけではかえってトンネル覆工の断面力が増加する場 合もあり，免震層の効果を議論するためには今後免震層の伸縮などを考慮に入れた検討が必要である. 